\title{
Tranexamic acid as an aid to reducing blood transfusion requirements in gastric and duodenal bleeding
}

\author{
CHRISTER C S STAËL voN HOLSTEIN，STEN B S ERIKSSON， RAGNAR KÄLLÉN
}

\begin{abstract}
A prospective randomised double blind study examined the effect of the antifibrinolytic drug tranexamic acid compared with placebo in 154 patients bleeding from verified benign lesions in the stomach or duodenum or both. Three out of 72 patients receiving tranexamic acid underwent emergency surgery compared with 15 out of 82 given placebo $(p=0.010)$. Nineteen patients receiving placebo rebled during their admission as compared with 10 in the active treatment group $(p=0.097)$. Blood transfusion requirements were significantly reduced by tranexamic acid $(p=0.018)$. Side effects occurred in six patients, of which an uncomplicated deep venous thrombosis was the most severe.
\end{abstract}

Tranexamic acid reduces the blood transfusion requirement and need for emergency surgery in patients bleeding from a benign gastric or duodenal lesion.

\section{Introduction}

Acute upper gastrointestinal bleeding is a common and life threatening condition with a mortality of around $10 \% .^{1-6}$ In the subgroup of patients needing emergency surgery to control bleeding mortality may be up to $30 \% .{ }^{37}$ Hence we need to find an efficient medical haemostatic regimen for these patients.

Fibrinolytic activity has been described in the stomach and duodenum and in the margins of peptic ulcers. ${ }^{8-13}$ Tranexamic acid is a potent antifibrinolytic drug with well documented effects on menorrhagia and haemorrhage after prostatic surgery. ${ }^{1416}$ Since 1973 five prospective randomised studies have been published

Department of Surgery, Central Hospital, Helsingborg, Sweden CHRISTER C S STAËL VON HOLSTEIN, MD, senior registrar STEN B S ERIKSSON, MD, PHD, consultant RAGNAR KÄLLÉN, MD, registrar

Correspondence to: Dr Sten Eriksson, Department of Surgery, Lasarettet, S-251 87 Helsingborg, Sweden. on the use of tranexamic acid for upper gastrointestinal tract bleeding. ${ }^{17-21}$ The results were conflicting, but this may have been due to the heterogeneity of the patients studied. We have therefore undertaken a prospective randomised double blind study of a more homogeneous group of patients-that is, patients with a verified benign gastric or duodenal lesion which was judged endoscopically to be the source of bleeding. The effect of tranexamic acid on the number of blood transfusions required, on rebleeding episodes, and on the need for urgent surgical interventions was studied.

\section{Patients and methods}

All patients admitted to this hospital between 24 October 1982 and 31 October 1984 with suspected upper gastrointestinal bleeding were managed according to a protocol, relevant data subsequently being recorded. Patients were not entered into the study if they had thromboembolic disease, bleeding or coagulation defects, were taking anticoagulants, or were pregnant.

Patients were randomised in batches of 10 and allocated to receive either tranexamic acid (Cyklokapron, KabiVitrum AB, Sweden) or placebo in addition to the usual conservative treatment. Tranexamic acid or placebo was initially given intravenously $1 \mathrm{~g}$ every four hours for three days followed by oral treatment with $1.5 \mathrm{~g}$ every six hours for a further three days. Placebo, whether intravenous or oral, was indistinguishable from the active drug. Treatment was begun within two hours of admission and was to be discontinued only if severe side effects or established rebleeding occurred or the patient needed emergency surgery. The additional standard treatment given to all patients included the introduction of a nasogastric tube through which every second hour an antacid was administered $(10 \mathrm{ml}$ Novaluzid, Hässle, Sweden) with a buffering capacity of $85 \mathrm{mmol}(3 \cdot 1 \mathrm{~g})$ hydrochloric acid. Endoscopy was performed, usually within 24 hours of admission, and any patient without a demonstrable benign gastric or duodenal lesion judged as the bleeding source excluded. Also excluded were patients with impaired renal function (serum creatinine concentration above $200 \mu \mathrm{mo} / 1 / 2 \cdot 3 \mathrm{mg} /$ $100 \mathrm{ml}$ )), since we judged it impossible to perform an accurate individual dose reduction for these patients.

When the patients began taking food by mouth, usually on the third day, the antacid regimen was changed to $10 \mathrm{ml}$ Novaluzid one and three hours after meals and $20 \mathrm{ml}$ at bedtime. Patients with proved peptic ulcers then also received cimetidine $400 \mathrm{mg}$ twice daily or, in 15 cases (seven patients in the tranexamic acid group, eight in the placebo group), ranitidine $150 \mathrm{mg}$ twice daily. Day to day management was left to the consultant in charge of each patient. 
The following departmental guidelines were issued and agreed on before the study. Transfusion of blood should be given if the patient had unstable circulation or the haemoglobin concentration dropped below $90 \mathrm{~g} / \mathrm{l}$ and continued until it reached $100 \mathrm{~g} / \mathrm{l}$. Emergency surgery was considered to be warranted when either there was severe continuous bleeding or the number of transfused units of blood exceeded six or whenever there were signs of rebleeding with unstable circulation. Rebleeding was defined as bleeding after a silent period of more than six hours or if there was a sudden drop in the haemoglobin concentration of some $20 \mathrm{~g} / 1$ or more. The protocol stated that to be included in the final evaluation the patient should have received at least 18 intravenous and 10 oral doses of the test drug or been withdrawn earlier because of emergency surgery or established rebleeding. The number of blood transfusions for each patient was calculated up to the time of discharge from hospital or the start of an emergency operation. All patients were followed up for six weeks.

After rechecking all the data on patients the treatment code was broken. The study was approved by the ethical committee of the University of Lund and by the Swedish National Board of Health and Welfare.

Size of trial-We calculated that at least 150 patients would need to be randomised for the trial. This number was based on a minimum probability of $80 \%$ and a statistical significance level of less than $5 \%$ to detect an assumed mean difference in blood loss of $500 \mathrm{ml}(\mathrm{SD} 600 \mathrm{ml})$ between the tranexamic acid and placebo treated patients.

Statistical methods-We evaluated differences in the numbers of emergency operations and episodes of rebleeding using the two tailed Fisher exact test. ${ }^{22}$ The difference in numbers of blood transfusions given was evaluated in the following way. Firstly, we compared the percentages of patients in the two treatment groups who did not receive any blood transfusions at all. Then the distribution of the number of units given was tested using the two tailed Armitage-Cochran test for trend. ${ }^{23}$ The number of patients transfused with $1-2,3-4,5-6$, or $>6$ units was considered as the independent variable and the proportion between treatment with tranexamic acid and placebo as the dependent one. As two consecutive calculations were performed, the resulting $p$ value was doubled.

Patients withdrawn-A total of 328 patients entered the study initially, of whom 174 were excluded from the final evaluation (table I). The most

TABLE I-Reasons for withdrawal among patients withdrawn according to preset criteria and among those intended for treatment

\begin{tabular}{|c|c|c|c|}
\hline \multicolumn{2}{|c|}{$\begin{array}{l}\text { Patients withdrawn according to } \\
\text { preset criteria }\end{array}$} & \multicolumn{2}{|l|}{$\begin{array}{l}\text { Withdrawals among patients } \\
\text { intended for treatment }\end{array}$} \\
\hline Reason for withdrawal & $\begin{array}{c}\text { No of } \\
\text { patients }\end{array}$ & Reason for withdrawal & $\begin{array}{c}\text { No of } \\
\text { patients }\end{array}$ \\
\hline $\begin{array}{l}\text { Oesophageal bleeding } \\
\text { Gastric carcinoma } \\
\text { No bleeding source in stomach or } \\
\text { duodenum } \\
\text { Thromboembolic disease } \\
\text { Coagulopathies } \\
\text { Impaired renal function }\end{array}$ & $\begin{array}{r}21 \\
8 \\
78 \\
5 \\
2 \\
12\end{array}$ & $\begin{array}{l}\text { Coexisting serious medical condition } \\
\text { Patient refused further treatment } \\
\text { Technical problems } \\
\text { Adverse drug reactions }\end{array}$ & $\begin{array}{r}22 \\
16 \\
7 \\
3\end{array}$ \\
\hline Total & 126 & & 48 \\
\hline
\end{tabular}

common reason for exclusion was that no gastric or duodenal source of bleeding could be found at endoscopy. Forty eight of the excluded patients were initially intended to receive full treatment. Owing to misunderstandings and technical problems, however, seven of these patients did not fulfil the protocol requirements for participation in the final evaluation. Twenty two other patients had coexisting diseases for which the consultant in charge considered that treatment and follow up according to our protocol were inappropriate, and 16 patients who initially agreed to the study later changed their minds. Only three patients, all in the tranexamic acid treated group, discontinued treatment because of side effects during the first few intravenous injections (nausea, vomiting, tachycardia, or hypotension).

\section{Results}

Of the 154 patients remaining for the evaluation, 72 had received tranexamic acid and 82 placebo. Statistical analysis showed that the two groups were comparable in age and sex distribution, source and severity of bleeding, and endoscopic stigmata of haemorrhage (table II). Most of the patients bled from peptic ulcers. In only six patients were erosions judged to be the definitive source of bleeding. The arterial malformation exulceratio simplex Dieulafoy ${ }^{24}$ caused bleeding in four patients.
TABLE II-Comparability of treatment groups

\begin{tabular}{lll}
\hline & $\begin{array}{c}\text { Tranexamic acid } \\
\text { group }\end{array}$ & $\begin{array}{c}\text { Placebo } \\
\text { group }\end{array}$ \\
\hline No of patients studied & 72 & 82 \\
No of men/women & $50 / 22$ & $58 / 24$ \\
Mean age (years) (range) & $62 \cdot 4(18-87)$ & $65 \cdot 4(32-95)$ \\
No with history of syncope before admission & 13 & 17 \\
Findings on admission: & 12 & 9 \\
No with unstable circulation & $98 \cdot 2(52-148)$ & $97 \cdot 6(50-169)$ \\
Mean haemoglobin (g/1) (range) & 137 & 133 \\
Mean systolic blood pressure (mm Hg) & 4 & 7 \\
No with systolic blood pressure <100 mm Hg & 94 & 91 \\
Mean pulse rate (beats/min) & $36(50)$ & $40(49)$ \\
No(\%) with blood in gastric aspirate & $2(3)$ & $2(2)$ \\
Endoscopic findings: & $17(24)$ & $25(30)$ \\
No (\%) with visible vessel in ulcer base & $8(11)$ & $14(17)$ \\
No (\%) with fresh bleeding & $29(40)$ & $24(29)$ \\
No (\%) with clot adherent to ulcer base & $16(22)$ & $17(21)$ \\
No (\%) with black staining of ulcer base & & \\
No (\%) with no stigmata of recent bleeding & $30(42)$ & $30(37)$ \\
Source of bleeding: & $36(50)$ & $39(48)$ \\
No (\%) with gastric ulcer & 1 & 3 \\
No (\%) with duodenal ulcer & 4 & 2 \\
No with stomal ulcer & 1 & 4 \\
No with gastric erosions & 0 & 4 \\
No with Mallory-Weiss tear & & \\
No with exulceratio simplex Dieulafoy & & \\
\hline
\end{tabular}

${ }^{\star}$ As judged by admitting doctor.

Blood transfusions-Tranexamic acid significantly reduced the number of blood transfusions given to each patient $(p=0.018)$ (table III). The mean $V$ number of units infused in the active treatment group was $2 \cdot 2$ and in the $\mathrm{O}$ control group $3 \cdot 2$. Mean haemoglobin concentrations at discharge were $\omega$ similar in the two groups (116.6 $\mathrm{g} / \mathrm{l}$ (range 90-153) and $116.9 \mathrm{~g} / \mathrm{l}$ (range 85-158) respectively).

TABLE III-Blood transfusion requirements among patients in the two treatment groups

\begin{tabular}{lcccccc}
\hline & \multicolumn{6}{c}{ Units transfused } \\
\cline { 2 - 6 } & 0 & $1-2$ & $3-4$ & $5-6$ & $>6$ & Total \\
\hline No in tranexamic acid group & 25 & 19 & 20 & 4 & 4 & 72 \\
No in placebo group & 28 & 15 & 14 & 10 & 15 & 82 \\
\hline
\end{tabular}

Armitage-Cochran test for trend, two tailed: $p=0.018$.

Rebleeding-More patients in the placebo treated group rebled, but the difference was not statistically significant (table IV). Thirteen patients had continuous bleeding and were thus omitted from the analysis of rebleeding.

Emergency surgery-Table $\mathrm{V}$ shows that treatment with tranexamic acid $\exists$ significantly reduced the need for emergency surgery $(p=0 \cdot 010)$. In retrospect two further patients, one in each group, fulfilled the criteria warranting emergency surgery but were not operated on.

Complications and deaths-Three patients treated with tranexamic acid suffered complications compared with none of the controls. Two had N superficial thrombophlebitis at the site of the intravenous injection and one patient developed an uncomplicated deep venous thrombosis one week after admission. Six of the 154 patients in the final evaluation died during the six week observation period. One patient receiving active treatment had a $\tilde{N}$ massive continuous bleed but refused surgery. Another died of colonic

TABLE IV—Patients rebleeding in the two treatment groups, stratified by diagnosis ${ }^{\star}$

\begin{tabular}{lccc}
\hline & $\begin{array}{c}\text { No in } \\
\text { tranexamic group } \\
(\mathbf{n}=69)\end{array}$ & $\begin{array}{c}\text { No in } \\
\text { placebo group } \\
(\mathbf{n}=72)\end{array}$ \\
\hline Gastric ulcer & 4 & 9 \\
Duodenal ulcer & 6 & 8 & 1 \\
Stomal ulcer & 0 & 1 \\
Exulceratio simplex Dieulafoy & 0 & 19 (17 to 38) \\
\hline Total (95\% confidence interval) & $10(7$ to 25$)$ & \\
\hline
\end{tabular}

ॠThirteen patients had continuous bleeding and were thus omitted from this analysis.

Fisher's exact test, two tailed: $p=0.097$. 
TABLE V—Patients subjected to emergency surgery, stratified by diagnosis

\begin{tabular}{lcc}
\hline & $\begin{array}{c}\text { No in } \\
\text { tranexamic acid group } \\
(\mathbf{n}=72)\end{array}$ & $\begin{array}{c}\text { No in } \\
\text { placebo group } \\
(\mathrm{n}=82)\end{array}$ \\
\hline Gastric ulcer & 2 & 6 \\
Duodenal ulcer & 1 & 5 \\
Exulceratio simplex Dieulafoy & 0 & 3 \\
Mallory-Weiss tear & 0 & 1 \\
\hline Total (95\% confidence interval) & $3(1$ to 12) & 15 (11 to 28)
\end{tabular}

Fisher's exact test, two tailed: $p=0 \cdot 010$.

carcinoma with metastases. There were four deaths in the placebo group, one due to massive rebleeding, two to myocardial infarction, and one to late renal failure after surgery.

\section{EXCLUDED PATIENTS INITIALLY INTENDED TO COMPLETE TRIAL}

As stated above, 48 patients were withdrawn from the study despite our intention that they should receive full treatment (table I). Had they been included the difference in blood transfusion requirements would have achieved greater statistical significance $(p=0.002)$. Three of the 48 patients underwent emergency surgery, two in the active treatment group and one given placebo. When these patients are added emergency surgery was performed on five of the 94 tranexamic acid treated patients compared with 16 of the 108 patients given placebo $(p=0.036)$.

\section{Discussion}

In this study tranexamic acid significantly reduced the blood transfusion requirements and number of emergency operations needed in patients with bleeding from benign lesions in the stomach and duodenum. Similar results reported by Biggs et al in $1976^{18}$ were not confirmed either by Engqvist et $a l^{19}$ or by Bergqvist et al. ${ }^{20}$ The latter two studies, however, included only patients with all types of massive bleeding, and we consider that antifibrinolytic treatment is less likely to be successful in large arterial or variceal haemorrhages.

In the largest trial reported Barer et al studied 775 patients stratified among three different treatment arms-namely, tranexamic acid, cimetidine, and placebo. ${ }^{21}$ They found a significantly reduced mortality associated with both active drugs but could not find any effect on blood transfusion requirements or the incidence of rebleeding and emergency operations. To see if there were any differences in the composition of patients included in the studies of Biggs and Barer and colleagues in relation to our own we compared the inclusion criteria, admission data, and outcome of the placebo treated patients in the three series. We conclude that the series were comparable. Thus Biggs et al operated on $19 \%$ (16/84) of their placebo treated patients with gastric or duodenal ulcers or erosions, Barer et al 17\% (25/143), and we 18\% (15/82). Barer et al stated that $25 \%$ of their patients rebled, which compares with the $23 \%$ in our study; we, however, used a different definition of rebleeding. Mortality also lay within random variation in the two latter studies ( $15 / 143$ and $4 / 82$ cases respectively). The mean number of blood transfusions given to each patient, however, was higher in the series of Barer et al (5.7 units) than in ours (3.2 units). This might be explained by a different blood transfusion policy and the fact that we counted units transfused only up to the start of emergency surgery. Furthermore, patients in the series of Barer et al may have bled more severely, $70 \%$ of their patients with rebleeding being operated on as a matter of urgency as compared with $20 \%$ in our series. On the other hand, our policy was early surgery for patients reaching a transfusion requirement of six units, so that many patients in our series potentially likely to rebleed may never have had the opportunity to do so. Probably this explains why rebleeding in our series was of less clinical importance. We do not think that regional differences in the composicion of patients could explain the differences between the two studies.
Table II shows that our two treatment groups were similar from a prognostic point of view. In a large multicentre trial De Dombal et al related the prognosis to clinical data at the time of admission for patients with upper gastrointestinal bleeding. ${ }^{25}$ Similar clinical data in our patients were evenly distributed between the active and placebo treatment groups. In both groups half of the patients were bleeding at the time of admission as judged from the gastric aspirate. Foster et $a l,{ }^{26} \mathrm{Griffiths} e t a l,{ }^{27}$ and Brearley $e t a l^{28}$ showed that certain endoscopic stigmata are associated with a high incidence of rebleeding and a poor prognosis. In our series endoscopy was performed an average of 17 hours after admission (and at least 15 hours after beginning treatment). At endoscopy one in five patients in both groups did not show any stigmata from recent bleeding. Nevertheless, a larger proportion of placebo treated patients were found to be actively bleeding or to have an adherent clot in the ulcer base. This difference, though not statistically significant, might be interpreted as a true difference in the distribution of prognostically unfavourable signs but may also have been caused by the treatment.

The design of our trial differed from others. In preparing the protocol we considered three important factors. Firstly, published data on the possible importance of fibrinolysis were available only for lesions in the stomach and duodenum. ${ }^{8.13}$ Secondly, an antifibrinolytic drug should be given intravenously in order to obtain optimal serum and tissue concentrations. ${ }^{17}{ }^{29}$ Finally, we judged it important to give the drug as soon as possible after admission, as the clinically unstable period is relatively short in patients with upper gastrointestinal bleeding. These issues made it impossible to use endoscopic findings to stratify the patients and also meant the exclusion of patients whose source of bleeding was the oesophagus or malignant tumours. In retrospect we regret that we did not foresee the "high" incidence of exulceratio simplex Dieulafoy.

We anticipated that many patients would be excluded from the trial by virtue of the preset criteria but considered this to be justified in view of the few side effects of the drug, and we do not believe that this influenced the validity of the final results. Moreover, the procedure resembled the normal clinical setting, where decisions are taken continuously during the process of hospital care.

Another essential difference compared with other studies may be in our strict antacid regimen. Barer et al allowed "free use of antacids and other remedies,"21 while other investigators did not state their policy in this respect. In vitro experiments by Green et al showed that acid and acid and pepsin in combination are capable of producing profound alterations in the coagulation cascade and that their capacity to disintegrate platelet aggregates is substantial..$^{30}$ Proteolytic activity by pepsin on experimental blood clots is, however, virtually abolished at a $\mathrm{pH}$ above $4 \cdot 0 .{ }^{31}$ On the other hand, gastric juice from patients with bleeding ulcers was found to have a plasmin like fibrinolytic activity. ${ }^{32}$ Antacids have not been proved to be effective as sole treatment for established bleeding ${ }^{33}$ but given prophylactically they prevent bleeding in patients at risk of upper gastrointestinal tract bleeding. ${ }^{34}{ }^{35}$ Antifibrinolytic treatment and an increase in gastric $\mathrm{pH}$ are possibly the necessary combination for successful haemostatic treatment.

In the treatment of conditions associated with low mortality other factors become important, such as cost benefit considerations. Our series included all patients with upper gastrointestinal tract bleeding admitted during two years from a well defined hospital catchment area. The total mortality was only $5 \cdot 8 \%$ (19/328). The drug studied had few side effects and saved blood transfusions and surgical resources.

We conclude that in patients bleeding from benign lesions in the stomach or duodenum it may be of value to add tranexamic acid to the conventional medical treatment.

We thank KabiVitrum AB for supplying the active and placebo substances and colleagues and nursing staff at the Central Hospital, Helsingborg, for invaluable help throughout. We acknowledge with special gratitude the advice from clinical trials manager Margareta Schannong, KabiVitrum AB, about the trial design and Rein Maasing regarding the statistical analyses. We also thank Mrs Inga Burstedt and Mrs Gun Hellberg for enthusiastic administrative work. 


\section{References}

1 Allan R, Dykes P. A study of the factors influencing mortality rates from gastrointestina haemorrhage. Qf Med 1976;45:533-50.

2 Himal H, Watson W, Jones C, Miller L, Maclean L. The management of upper gastrointestina hemorrhage: a multiparametric computer analysis. Ann Surg 1974;179:489-93.

3 Crook J, Gray L Jr, Nance F, Cohn J. Upper gastrointestinal bleeding. Ann Surg 1972;175:771-9. 4 Macleod J, Mills P. Factors identifying the probability of further haemorrhage after acute upper gastrointestinal haemorrhage. Br f Surg 1982;69:256-8.

5 Johnston S, Jones P, Kyle J, Neddham C. Epidemiology and course of gastrointestinal haemorrhage in north-east Scotland. BrMed J 1973;iii:655-60.

6 Hunt PS, Francis JK, Hansky J, et al. Reduction in mortality from upper gastrointestinal haemorrhage. Med J Aust 1983;ii:552-5.

7 Vellacott K, Dronfield M, Atkinson M, Langman M. Comparison of surgical and medical management of bleeding peptic ulcers. Br Med f 1982;284:548-50.

8 Cox H, Poller L, Thomson J. Gastric fibrinolysis. A possible aetiological link with peptic ulcer. Lancet 1967; i:1300-2.

$9 \mathrm{Cox} \mathrm{H}$, Poller $\mathrm{L}$, Thomson J. Evidence for the release of gastric fibrinolytic activity into periphera blood. Gut 1969;10:404-7.

10 Thomson J. Fibrinolysis and the stomach. Biochemical identification of the "plasmin like" enzyme. Thrombosis et Diathesis Haemorrhagica 1974;31:291-8.

11 O'Brien T, Hadley H, Irving M. Fibrinolytic activity in gastric venous blood. Gastroenterolog 1979;76:509-14.

12 Eras P, Harpel P, Winaver S. Histological localisation of plasminogen activator and proteolytic activity in the human stomach and duodenum. Gut 1970;11:851-4.

13 Kondo M, Ikezaki M, Imanishi H, Nishigaki I, Nakai T, Hosokawa K. Role of tissue fibrinolytic activity in gastroduodenal ulcer. Foumal of the Kyoto Prefectural University of Medicine 1975;84: $1021-7$.

14 Callender S, Warner G, Cope E. Treatment of menorrhagia with tranexamic acid. A double-blind trial. BrMed f 1970;iv:214-6.

15 Vermylen J, Verhaegen-Declercq M, Verstraete M, Fierens F. A double-blind study of the effect of tranexamic acid in essential menorrhagia. Thrombosis et Diathesis Haemorrhagica 1968;20: 583-7.

16 Hedlund PO. Antifibrinolytic therapy with Cyklokapron in connection with prostatectomy. A double-blind study. Scand $\mathcal{F}$ Urol Nephrol 1969;3:177-82.

17 Cormack F, Chakrabarti RR, Jouhar AJ, Fearnley GR. Tranexamic acid in upper gastrointestina haemorrhage. Lancet 1973;i:1207-8.

18 Biggs J, Hugh T, Dodds A. Tranexamic acid and upper gastrointestinal haemorrhage-a doubleblind trial. Gut 1976;17:729-34.
19 Engqvist A, Boström O, Feilitzen F, et al. Tranexamic acid in massive haemorrhage from the upper gastrointestinal tract: a double-blind study. Scand $\mathcal{F}$ Gastroenterol 1979;14:839-44.

20 Bergqvist $D$, Dahlgren $S$, Hessman $Y$. Local inhibition of the fibrinolytic system in patients with massive upper gastrointestinal haemorrhage. Ups $\mathcal{f}$ Med Sci 1980;85:173-8.

21 Barer $\mathrm{D}$, Ogilvie A, Henry $\mathrm{O}$, et al. Cimetidine and tranexamic acid in the treatment of acute upper-gastrointestinal-tract bleeding. $N$ Engl f Med 1983;308:1571-5.

22 Cochran W. Some methods for strengthening the common $\chi^{2}$ tests. Biometrics 1954;10:417-51. C

23 Armitage P. Statistical methods in medical research. Oxford and Edinburgh: Blackwell Scientific, 1971:363-5.

24 Broberg A, Ihre T, Pyk E. Exulceratio simplex as a conceivable cause of massive gastric

25 De Dombal FT, Clarke JR, Clamp S, Malizia G, Kotwal MR, Morgan AG. Prognostic factors in upper GI bleeding Endoscopy 1986;18(suppl 2):6-10.

26 Foster DN, Miloszewski KJA, Losowsky MS. Stigmata of recent haemorrhage in diagnosis and prognosis of upper gastrointestinal bleeding. Br Med 7 1978;i11173-7.

27 Griffiths $W$, Neumann $D$, Welsh J. The visible vessel as an indicator of uncontrolled or recurrent gastrointestinal hemorrhage. N Engl I Med 1979;300:1411-3.

28 Brearley S, Morris DL, Hawker PC, Dykes PW, Keighley MRB. Prediction of mortality at endoscopy in bleeding peptic ulcer disease. Endoscopy 1985;17:173-4

29 Andersson L, Nilsson IM, Colleen S, Granstrand B, Melander B. Role of urokinase and tissue $\frac{\bar{O}}{\sigma}$ activator in sustaining bleeding and the management thereof with EACA and AMCA. Ann NY $\overline{\bar{S}}$ Acad Sci 1968;146:642-58.

30 Green F Jr, Kaplan M, Curtis L, Levine P. Effect of acid and pepsin on blood coagulation and $\mathbb{D}$ platelet aggregation. A possible contributor to prolonged gastroduodenal mucosal hemorrhage.
Gastroenterology 1978;74:38-43.

31 Berstad A. Management of acute upper gastrointestinal bleeding. Scand $\mathcal{f}$ Gastroenterol $\vec{O}$ 1982;17(suppl 75):103-8.

32 Buhr H, Encke A, Seufert R. Untersuchungen zur lokalen Fibrinolyse des Magens. Chinurg 1978; $\rightarrow$ 49.431-5.

33 Kittang E, Aadland E, Oyen D, et al. Effect of peroral treatment of patients with acute upper gastrointestinal haemorrhage: a randomized controlled trial. Scand $\mathcal{f}$ Gastroenterol 1982; 17(suppl 75):109-12.

34 Hastings $P$, Skillman J, Bushnell $L$, Silen $W$. Antacid titration in prevention of acute gastrointestinal bleeding. A controlled, randomized trial in 100 critically ill patients. $N$ Engl $f$ N Med 1978;298:1041-5.

35 McAlhany J Jr, Colmic L, Czaja A, at al. Antacid control of complications from acute gastroduodenal disease after burns. F Trauma 1976;16:645-8.

(Accepted 7 October 1986)

\title{
Reproduction of epigastric pain of duodenal ulceration by adenosine
}

\author{
ANDREW H WATT, DAVID J M LEWIS, JOHN J HORNE, PAUL M SMITH
}

\begin{abstract}
Intravenous boluses of adenosine produced transient epigastric discomfort indistinguishable from spontaneous pain in five of six patients with endoscopically confirmed duodenal ulcer, an effect which was slightly but significantly antagonised by aminophylline.

These findings may be relevant to the pathophysiology of peptic ulcer pain.
\end{abstract}

\section{Introduction}

Adenosine is an endogenous nucleoside, much of which is formed as a metabolite of the nucleotide adenosine triphosphate (ATP). Adenosine exerts various pharmacological effects, including vasoDepartment of Pharmacology and Therapeutics, University of Wales College
of Medicine, Cardiff CF4 4XN

ANDREW H WATT, BMEDBIOL, MRCP, clinical research officer

Department of Medicine, Bridgend General Hospital, Bridgend, Mid Glamorgan

DAVID J M LEWIS,

Department of Medicine, Llandough Hospital, Llandough, South Glamorgan JOHN J HORNE, MB, MRCP, medical registrar

PAUL M SMITH, MD, FRCP, consultant physician

Correspondence to: Dr Watt dilatation and cardiac electrophysiological effects. ${ }^{1}$ While investigating the respiratory stimulant effect of adenosine $e^{2}$ one subject $(a \stackrel{-}{-}$ colleague who had not disclosed that he had a duodenal ulcer) reported that intravenous boluses of adenosine produced epigastric pain that did not differ from his spontaneous ulcer pain, except that it was transient.

Little attention had been paid to the capacity of adenosine to produce or modulate pain with the exception of a study of pain induced by adenosine on a human blister base preparation. ${ }^{3}$ Thus $\frac{\text { }}{3}$ the study aimed at determining whether the adenosine induced N epigastric pain observed in our subject occurred in other subjects with symptomatic duodenal ulcer, whether the pain was related to the dose given, and whether any pain that occurred was modified by aminophylline, a competitive antagonist at cell surface adenosine receptors.

\section{Patients and methods}

Informed, written consent was obtained from six patients (four men) aged $T$ 25-62 with endoscopically proved duodenal ulcers that had been sympto- $\frac{O}{\Phi}$ matic in the week before the study. Two patients with recurrent duodenal $\stackrel{D}{\triangle}$ ulceration had been treated with cimetidine in the past. No patient was taking $\mathrm{H}_{2}$ antagonists at the time of study, and no patient had taken oral $\bar{\sigma}$ antacids on the study day. It was made clear to each patient that the purpose of the study was to determine whether adenosine could mimic theiro spontaneous ulcer pain, that any pain was expected to last only a few seconds after any one bolus injection, and that after any injection the study would beco stopped at their request. The study protocol was approved by the hospital $\stackrel{P}{\rightleftharpoons}$ ethics committee. 